\title{
A Systematic Literature Review of the Roles, Financing Mechanisms, and Working Capital Under Supply Chain Finance
}

\author{
Jun-Zhi Chiu' ${ }^{1}$ \\ *Chao-Chen Hsieh ${ }^{2}$
}

Supply chain finance (SCF) is a technology-based business model that companies use to ensure the upstream and downstream participants in their supply chains can access trade credit and improve cash flow at a low cost (Camerinelli, 2009; Lamoureux and Evans, 2011). SCF refers to "the intercompany optimization of financing as well as the integration of financial processes with customers, suppliers, and service providers in order to increase the value of all participating companies" (Gomm and Pfohl, 2009).

From the collateral perspective, SCF builds on mutual trust or offers non-binding options in contractual relationships. Borrowers and lenders register creditworthiness and trade history when utilizing financial instruments such as advance payment and dynamic discounts, as well as trade credit (Navas-Alemán et al., 2012). From the perspective of risk mitigation, SCF constitutes a wide spectrum of effective instruments, tools, and models that enable firms to reduce their working capital requirements (Babich and Kouvelis, 2018) without damaging the health of the supply chain. One short-term financing option available to businesses is trade credit, in which suppliers allow a small business to postpone payment for the products or services it purchases. More complex credit requirements are addressed by obtaining loans from financial institutions. Extended by sellers to buyers, trade credit allows goods or services to be purchased from the former without making immedi- 
ate payment and, as such, is an important source of short-term finance available to businesses. More and Basu (2013) classifies the forms of trade credit according to the different stages of a supply chain operation: pre-transportation financing (e.g., for raw materials or orders), in-transit (inventory) financing, and post-transportation financing (such as advanced payment financing, or accounts receivable).

SCF has been extensively researched in recent years. It focuses on creating liquidity between seller and buyer via a facilitating technology (Babich and Kouvelis, 2018). SCF is also a dynamic solution that leverages the buyer's payable accounts without adding any financial debt to either the buyer's or supplier's balance sheet. Song et al. (2018) indicate that SCF enables SMEs (small and mediumsized enterprises) to receive guarantees from suppliers. With SCF, loans can be secured from banks or financial institutions based on previous transactions and purchasing information. Additionally, some research has considered the prepayment finance, financial institutions will provide to supplier of advanced, enabling them to guarantee that a commodity will reach a buyer in the future. This is supported by contractual arrangements and cash-flows between buyers and sellers ( He and Tang, 2012).

The financial perspective on SCF focuses on the liquidity invested in supply chain processes and transactions (Babich and Kouvelis, 2018) and the effectiveness of working capital flow. In sum, SCF mechanisms reduce the need for working capital while optimizing its flow, thereby benefiting buyers and sellers in the supply chain. However, previous studies have rarely investigated working capital, the role of financial institutions, and the mechanisms of coordination in SCF.

The study contributes to SCF research in the following ways. First, the approach we deployed to textual analysis makes a useful methodological contribution to systematic reviews of literature. Second, our analysis of research papers identifies contemporary SCF topics by evaluating the relative importance of key terms related to the field. Third, the identification of credit term changes points towards a framework for analyzing working capital and actionable ideas for future research into supply chain financing.

The remainder of the paper is structured as follows: Section 2 contains the literature review, data, methodology used, and descriptive analysis, while Section 3 presents the results of the term frequency-inverse document frequency (TF-IDF) analysis and Section 4 summarizes the results. Finally, Section 5 discusses the findings and limitations of this study.

\section{LITERATURE REVIEW}

\section{The Role of SCF}




\section{Chiu \& Hsieh}

Small and medium enterprises (SMEs) play a significant role in the development of economies (Navas-Alemán et al., 2012). However, such businesses face a major barrier to their growth: financing. Credit crunches, shortages, and high borrowing costs all create obstacles to SMEs, which require access to risk-free credit to manage their net working capital (Randall and Farris, 2009; Song et al., 2018). Without liquidity to support investment and innovation, economic growth suffers. If liquidity can be released into the working capital of supply chains, these will grow more robust and competitive, boosting economies more generally. It is therefore worth considering how to establish credit information sharing mechanisms that promote bank lending to SMEs.

The role of SCF is to optimize both the availability and cost of capital within a given supply chain. The recent increase in scientific articles focusing on SCF has defined the concept more clearly, enabling the SCF solutions landscape to be described with greater precision.

\section{SCF Mechanisms}

The literature has defined SCF in a strategically ambiguous and somewhat impractical fashion. However, this broad definition has attracted wide attention and endorsement for its potential for optimizing financial flow and creating value (Hofmann, 2005). By 2000, different understandings of the term SCF had begun to appear (Hofmann, 2005), with some accounts suggesting that varying forms of SCF could be designed in line with transaction relations within the supply chain, generating several financing models (Klapper, 2006) and adding value. SCF has been widely touted to offer solutions to the problems faced by SMEs in availing finance; the literature on SCF confirmed that SCF improves accessibility to funds, particularly for smaller partners in supply chains.

Many different enterprises demand alternative forms of financing-particularly trade credit from suppliers. The availability of trade credit can be viewed as a sign of quality assurance by supplier when creating opportunities for high-tech or newly developed products (Emery and Nayar, 1998; Long et al., 1993). This also applies to supply chains, where competition among suppliers can provide trade credit for downstream retailers, allowing them to postpone payments and making the relationship between customers more robust (Fu et al., 2018). Meanwhile, trade credit can coordinate and enhance supply chain efficiency. A number of studies have emphasized the relationship between trade credit and supply chain performance. Research has also confirmed that suppliers and buyers can mutually benefit from enhancing inter-firm collaboration (Lee et al., 2018; Tang et al., 2018).

Reverse Factoring (RF), the most popular of all supply chain finance schemes, is used by large firms with high-quality credit ratings as a mechanism for ensuring their supply chains function smoothly (Caniato et al., 2016). RF involves a three-party arrangement between a buyer, a factor (usually a bank), and a supplier. In this arrangement, the buyer promises to pay the invoices from its 
trade transactions with the supplier to the factor, who undertakes to provide an approved invoicebased financing solution to the supplier. Tanrisever et al. (2015) demonstrate that the value of RF is greater when the credit spread is large, the payment extension period is short, the demand volatility is high, and the SME's working capital requirements are also relatively high. Transactions in the SCF mechanism are presented in Figure 1.

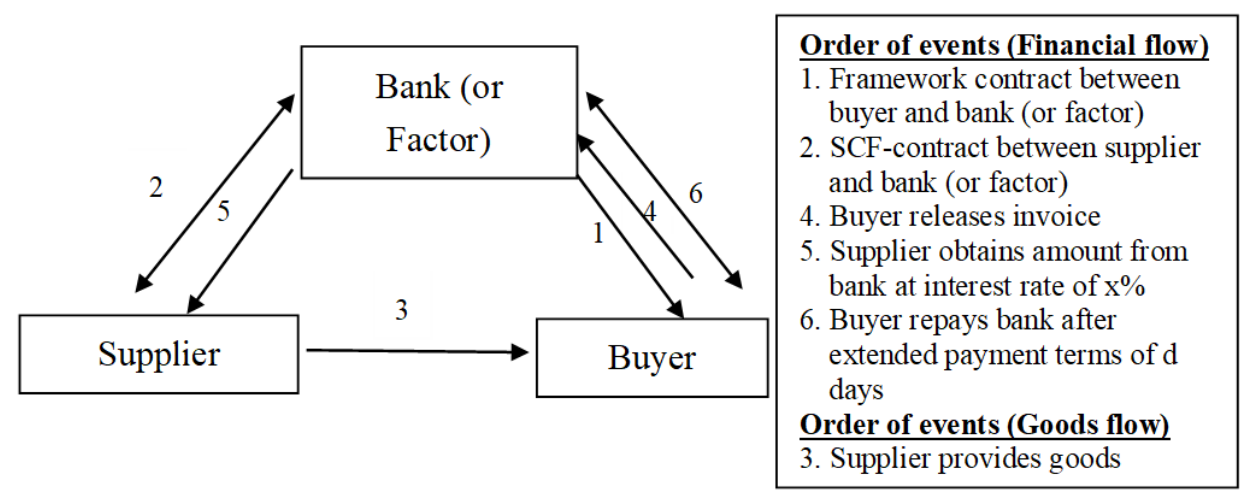

Source: Wuttke et al. (2013) and Caniato et al. (2016)

Figure 1. Transactions in the SCF mechanism

\section{Working Capital in SCF}

There is a need for better management and optimization of working capital in the supply chain which SCF provides. Working capital refers to financial liquidity and viability for participants in a supply chain and it is important to understand how firms can maximize their working capital when trade credit is part of their business transactions. While working capital has always been critical to every business, supply chain professionals' active engagement in coordinating financing in their area of expertise took off only in the last decade. SCF is now seen as a unique financial product of critical importance to all supply chain members since it can ensure they can access a ready supply of working capital if managed carefully. The ultimate objective is to flexibly adjust financial flows in the supply chain as well as improve cash flow management (Wuttke et al., 2013). The U.S. Federal Reserve System (2016) reported that accounts payable, i.e., the amount of trade credit owed by buyers to suppliers, were 3.3 times as large as bank loans on the aggregated balance sheet of non-financial US businesses. Therefore, it requires a disciplined approach to optimize cash flow management of business processes.

Randall and Farris (2009) indicated that inventories, receivables, and payables should be considered while making cash-to-cash cycle calculations in order to optimize capital in the supply chain. The cash-to-cash cycle approach also improves trust, commitment, and profitability througho- 


\section{Chiu \& Hsieh}

ut the chain. From this working capital management perspective, SCF offers a set of innovative financial solutions to short-term financing and particularly to managing receivables and payables.

Table 1 (see Appendix-I) shows the typical approaches taken to SCF. While the list of approaches to SCF provided is comprehensive and, in our opinion, involves many diverse practices fundamental to SCF, this paper focuses on those aspects that are closely related to short-term credit and links to finance. This goes beyond a purely financial perspective to consider the supply chain, its technologies, and the perspective of production economics more broadly.

\section{METHODOLOGY}

\section{-Sample and Procedure}

Our search centered on data from the Web of Science due to its wide selection of congeneric articles. To pre-process the text documents, all data were collected and organized based on indexing. After the appropriate search terms were defined and algorithms applied to remove stop words, the remaining words were stemmed to obtain tokenized terms. The weights of these terms were calculated using TF-IDF. The detailed steps taken to define an initial set of keywords and search structure are provided in Figure 2.

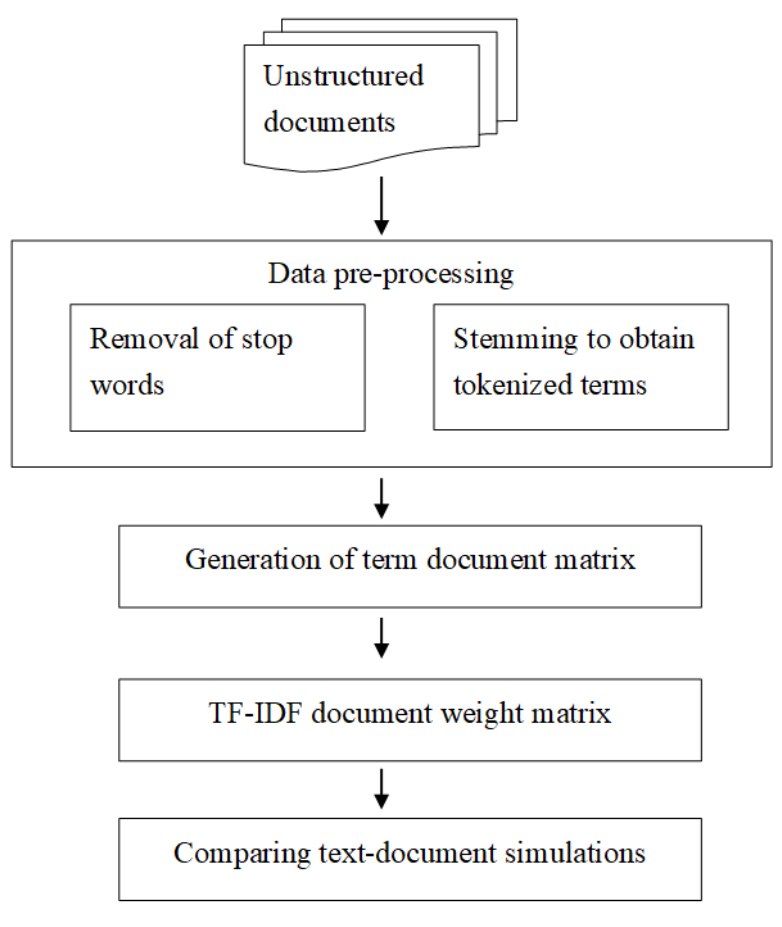

Source: Lydia et al. (2018)

Figure 2. The Literature Search Process 


\section{-Selection of Items for Analysis}

After source texts had been selected to ensure sufficient and appropriate topic coverage, the keywords within them were chosen. An initial set of keywords and search structure was established following the procedure described by Lydia et al. (2018). By searching irrelevant papers and research areas, the exclusion keywords could be identified, and the keyword structure was updated accordingly. The initial sample consisted of 618 articles published in 250 journals, whereas final sample comprised of 161 articles.

\section{-TF-IDF Framework for Text Categorization}

The frequency of keywords was extracted from the article abstracts. Prior to counting, the keywords were filtered to avoid duplicating keywords with identical meanings and to combine hyphenated words describing a single keyword. The TF-IDF algorithm produced successful results in the overall framework and testing process (Hsieh and Chiu, 2020).

\section{-Comparative Text Analysis}

Comparative text analysis showcased associations (e.g., between SCF, working capital, and trade credit) among the keywords and characterized the themes of the articles in a scientific field. These were described as keyword-based usage over time.

\section{RESULTS}

A deductive approach was taken to the initial literature classification of this study. When this was completed, we switched to an inductive, bottom-up approach to perform the citation analysis.

\section{Text Analysis based on TF-IDF of Keywords}

Our initial analysis identified 618 papers that had been published in more than 250 journals. Table 2 details our strategic search for the four roles of loan offer flow and the number of articles that contributed to each one. SCF, factoring, and working capital were the primary focus for many of the key journals identified. However, the linkages between supply chain finance, trade credit, and working capital may demonstrate the significance of this research area within the general context of SCF and its optimization.

The text analysis characterized each of the themes in terms of their internal and external cohesion. The frequency of keywords was calculated to identify how SCF-related topics had changed over time in the publications of documents separately. Calculating the frequency of keywords allowed us to judge their relative importance in articles focused on SCF, trade credit, and working capital. Table 3 shows that the TF-IDF "1" weighting for the "capital-constrained" keyword was higher than the "0" wei- 


\section{Chiu \& Hsieh}

ghting for "replenishment". In other words, the "capital-constrained" keyword lending high discriminatory power to those documents.

\begin{tabular}{ccc}
\hline $\begin{array}{c}\text { Role } \\
\text { Loan offer flow) }\end{array}$ & Search of Keywords & $\begin{array}{c}\text { Frequency in the } \\
\text { Sample }\end{array}$ \\
\hline Supplier $\rightarrow$ Buyer & Supply chain finance and trade credit & 161 \\
\hline Buyer $\rightarrow$ Supplier & Supply chain finance and purchase order financing & 40 \\
\hline \multirow{2}{*}{$\begin{array}{c}\text { Buyer } \rightarrow \text { Supplier or } \\
\text { Supplier } \rightarrow \text { Buyer }\end{array}$} & Trade credit and working capital & 40 \\
\cline { 2 - 3 } & Trade credit and accounts payable & 4 \\
\hline Factor $\rightarrow$ Supplier & Trade credit and accounts receivable & 5 \\
\hline Source: Authors' Presentation & Trade credit and reverse factoring & 12 \\
\hline
\end{tabular}

Table 2. Strategic Search for the Four Roles of SCF

As shown in Table 3, "capital-constrained" and "replenishment" were the most-used keywords in both SCF and working capital research. In recent years, inter-corporate optimization of financing has become an important research topic in SCF-related fields. Moreover, SCF is also viewed as optimizing the management of the working capital and liquidity that has been invested, particularly for smaller SC partners.

\begin{tabular}{c|c|c|c|c|c}
\hline \multicolumn{2}{c|}{ SCF } & \multicolumn{2}{c}{ Trade Credit } & \multicolumn{2}{c}{ Working capital } \\
\hline Keywords & Frequency & Keywords & Frequency & Keywords & Frequency \\
\hline Sustainability & 69 & $\begin{array}{c}\text { Capital- } \\
\text { Constrained }\end{array}$ & 48 & Relationships & 14 \\
\hline $\begin{array}{c}\text { Capital- } \\
\text { Constrained }\end{array}$ & 49 & Deteriorating & 38 & $\begin{array}{c}\text { Revenue- } \\
\text { Sharing }\end{array}$ & 14 \\
\hline Replenishment & 40 & Replenishment & 35 & $\begin{array}{c}\text { Capital- } \\
\text { Constrained }\end{array}$ & 9 \\
\hline Deteriorating & 34 & Sustainability & 6 & Replenishment & 8 \\
\hline Collaboration & 28 & Credit-Market & 4 & Organizations & 6 \\
\hline
\end{tabular}

Source: Authors' Presentation

TF-IDF weighting for "capital-constrained" = 1; TF-IDF weighting for "replenishment" = 0

Table 3. Top 5 Keywords used in SCF, Trade Credit, and Working Capital Publications

\section{DISCUSSION}

The results afforded several interesting insights into the evolution of SCF over recent years. Our discussion will concentrate on two specific aspects: first, the dynamics of the strategic search for the four roles of SCF, and second, the frequency of keywords in terms of what they tell us about SCF research topics and their links to the transformation of credit terms. Our discussion of the dynamics of 
the strategic diagrams is based on three characteristics of the text: (a) type of central keyword defining the text, (b) major motor text, and (c) emerging text.

Particularly in Taiwan, SCF is perceived differently in credit terms. Working capital structure, capital constraints, and the financial performance of SMEs are of predominant importance as shown in Table 4. This finding corroborates with Vu Thi and Phung (2021) who attribute concerns with these aspects to the serious financial constraints faced by SMEs.

\begin{tabular}{c|c|c|c}
\hline Differences & SCF & Working Capital & $\begin{array}{c}\text { Major reason for } \\
\text { working capital in SCF }\end{array}$ \\
\hline Primary driver & $\begin{array}{c}\text { Optimize working capital } \\
\text { when trade credit is } \\
\text { present in business } \\
\text { transactions }\end{array}$ & $\begin{array}{c}\text { SMEs are unable to } \\
\text { access liquidity through } \\
\text { conventional banking } \\
\text { loans. Robust } \\
\text { relationships should be } \\
\text { built among SC } \\
\text { participants. }\end{array}$ & $\begin{array}{c}\text { Revenue-sharing. } \\
\text { Contracts can coordinate } \\
\text { the supply chain with } \\
\text { enough working capital. }\end{array}$ \\
\hline $\begin{array}{c}\text { Role of Bank (or } \\
\text { Financing mechanisms) }\end{array}$ & $\begin{array}{c}\text { Factoring } \\
\text { Reverse factoring }\end{array}$ & Reverse factoring \\
\hline
\end{tabular}

Table 4. A Comparison of SCF in Credit Terms

A proper capital structure and working capital will lead to success and maximize benefits for SME owners. However, revenue-sharing contracts can coordinate the supply chain only when enough total working capital is available. Moreover, suppliers cannot allocate profit flexibly unless their working capital is sufficiently large. At an advanced level, this issue originates from economic systems and financial institutions (Song et al., 2018; Vu Thi and Phung, 2021).

\section{CONCLUSION}

This paper has investigated the roles and mechanisms affecting supply chains covered by the SCF literature. Our systematic review found that financial liquidity and viability for supply chain participants were major concerns of this literature. After analyzing the frequency of keywords and evaluating their relative importance within our corpus of articles, we detected an increasing emphasis on the importance of working capital to the entire supply chain. Another point of emphasis was building robust relationships among supplier, customer, and service provider rather than optimizing their work in their business transactions.

One contribution of this study has been to show that revenue-sharing contracts can coordinate the supply chain with sufficient working capital to cover real-time response to demands, facilitating transparency and traceability in the flow of material, information and financial liquidity through the 


\section{Chiu \& Hsieh}

supply chain. This enables SMEs to obtain essential knowledge and share information in real-time with all supply chain partners. Another contribution has been to enhance awareness and create knowledge of prepayment finance, which financial institutions will pay to producers in advance and which allows sellers to guarantee the delivery of commodities (He and Tang, 2012).

\section{IMPLICATIONS}

The current study underlines the importance of the mechanisms and structure of working capital, capital constraints, and the financial performance of SMEs (Song et al., 2018; Vu Thi and Phung, 2021). In addition, our systematic review of the SCF literature revealed that the financial liquidity and viability of supply chain participants was a major theme. The review indicated that managers should ensure working capital is available across the whole supply chain and optimizing capital that encourage participants to see SCF as mutually beneficial.

\section{LIMITATIONS AND FUTURE DIRECTIONS}

The corpus of papers was taken only from the ISI Web of Science due to its comprehensive database of relevant articles, but other open-source databases may return additional articles and should be investigated by researchers in subsequent studies. Although its external validity may be limited by time, this study can be used as a baseline for comparison by researchers who investigate supply chain roles and mechanisms in the future.

\section{REFERENCES}

Babich, V., \& Kouvelis, P. (2018). Introduction to the special issue on research at the interface of finance, operations, and risk management (iFORM): Recent contributions and future directions. Manufacturing and Service Operations Management, 20, 1-160. https://doi.org/10.1287/msom.2018.0706

Camerinelli, E. (2009). Supply chain finance. Journal of Payments Strategy and Systems, 3, 114-128.

Caniato, F., Gelsomino, L. M., Perego, A., \& Ronchi, S. (2016). Does finance solve the supply chain financing problem? Supply Chain Management: An International Journal, 21(5): 534-549. http://dx. doi.org/10.1108/SCM-11-2015-0436

Devalkar, S. K., \& Krishnan, H. (2018). The impact of working capital financing costs on the efficiency of trade credit. Production and Operations Management, 28 (4): 878-889. http://dx.doi.org/10.1111/poms.12954

Emery, G., \& Nayar, N. (1998). Product quality and payment policy. Review of Quantitative Finance and Accounting, 10, 269284.

Federal Reserve System (2016). The Federal Reserve payments study. https://www.federalreserve.gov/paymentsystems/2016payment-study.htm

Fu, J., Matous, P., \& Yasuyuki, T. (2018). Trade credit in global supply chains. RIETI Discussion Paper Series, 18-E-049.

Gomm, M. \& Pfohl, H.C. (2009) Supply chain finance: optimizing financial flows in supply chains. Logistics Research, 1, 149161.

He, X.J., \& Tang, L.Y. (2012). Exploration on building of visualization platform to innovate business operation pattern of supply chain finance. Physics Procedia, 33(2): 1886-1893.

Hofmann, E. (2005). Supply chain finance: Some conceptual insights. Logistic Management, $203-214$. http://dx.doi.org/10.1007/978-3-322-82165-2_16

Hsieh, C.-C., \& Chiu, J.-Z. (2020). System review: A text analysis on supply chain finance. Universal Journal of Management, 8(2): 29-32. https://doi.org/10.13189/ujm.2020.080201

Klapper, L.F. (2006). The role of factoring for financing small and medium enterprises. Journal of Banking and Finance, 30(11): $3111-3130$ 
Kouvelis, P., \& Zhao, W. (2012). Financing the newsvendor: Supplier vs. bank, and the structure of optimal trade credit contracts. Operation Research, 60(3): 566-580. http://dx.doi.org/10.1287/opre.1120.1040

Lamoureux, J.F., \& Evans, T. (2011). Supply chain finance: A new means to support the competitiveness and resilience of global value chains. Social Science Research Network. http://dx.doi.org/10.2139/ssrn.2179944

Lee, H.-H., Zhou, J., \& Wang, J. (2018). Trade credit financing under competition and its impact on firm performance in supply chains. Manufacturing Service Operations Management, 20(1): 36-52. https://doi.org/10.1287/msom.2017.0640

Long, M., Malitz, I., \& Ravid, A. (1993). Trade credit, quality guarantees, and product marketability. Financial Management, 22(4): 117-127.

Luo, W., \& Shang, K.H. (2019). Technical note-managing inventory for firms with trade credit and deficit penalty. Operations Research, 67(2): 468-478. https://doi.org/10.1287/opre.2018.1787

Lydia, E.L., Kumar, K.V., Reddy, P.A., \& Ramya, D. (2018). Text mining with Hadoop: Document clustering with TF-IDF and measuring distance using Euclidean. Journal of Advanced Research in Dynamical and Control Systems, 10(14):1784.

Marak, Z.R., \& Pillai, D. (2018). Factors, outcome, and the solutions of supply chain finance: review and the future directions. Journal of Risk and Financial Management, 12(1): 1-23. https://doi.org/10.3390/jrfm12010003

More D., \& Basu P. (2013). Challenges of supply chain finance: A detailed study and a hierarchical model based on the experiences of an Indian Firm. Business Process Management Journal, 19(4): 624-647. http://dx.doi.org/10.1108/BPMJ-092012-0093

Navas-Alemán, L., Pietrobelli, C., \& Kamiya, M. (2012). Inter-firm linkages and finance in value chains. Working paper, InterAmerican Development Bank. http://hdl.handle.net/10419/89007

Randall, W., \& Farris, M. (2009). Supply chain financing: using cash-to-cash variables to strengthen the supply chain, International Journal of Physical Distribution \& Logistics Management, 39(8): 669-689. http://dx.doi.org/10.1108/09600030910996314

Reindorp, M, Tanrisever, F., \& Lange, A. (2018). Purchase order financing: credit, commitment, and supply chain consequences. Operations Research, 66(5): 1287-1303. http://dx.doi.org/10.1287/opre.2018.1727

Song, H., Yu, K., \& Lu, Q. (2018). Financial service providers and banks' role in helping SMEs to access finance. International Journal of Physical Distribution \& Logistics Management, 48(1): 69-92. https://doi.org/10.1108/IJPDLM-11-2016-0315

Tang, C.S., Yang, S.A., \& Wu, J. (2018). Sourcing from suppliers with financial constraints and performance risk. Manufacturing Service Operations Management, 20(1): 70-84. https://doi.org/10.1287/msom.2017.0638

Tanrisever, F., Cetinay, H. Reindorp, M., \& Fransoo, J.C. (2015). Reverse factoring for SME finance. Available at SSRN https://ssrn.com/abstract=2183991

Trstenjak, B., Mikac, S., \& Donko, D. (2014). KNN with TF-IDF based framework for text categorization. Procedia Engineering, 69, 1356-1364. https://doi.org/10.1016/j.proeng.2014.03.129

Vu Thi, A.-H., \& Phung, T.-D. (2021). Capital structure, working capital, and governance quality affect the financial performance of small and medium enterprises in Taiwan. Journal of Risk Financial Management, 14(8): 381 https://doi.org/10.3390/jrfm14080381.

Wuttke, D. A., Blome, C., \& Henke, M. (2013). Focusing the financial flow of supply chains: An empirical investigation of financial supply chain management. International Journal of Production Economics, 145(2): 773-789. http://dx.doi.org/10.1016/j.ijpe.2013.05.031

Zhan, J., Shuting L. S., \& Chen, X. (2018). The impact of financing mechanism on supply chain sustainability and efficiency. Journal of Cleaner Production, 205, 407-418. https://doi.org/10.1016/j.jclepro.2018.08.347

\section{ACKNOWLEDGMENT}

This work was supported by the National Science Council, Taipei, Taiwan, R.O.C., Project No. Grant MOST: 110-2637-E-166-001. 


\section{Chiu \& Hsieh}

Appendix-I

\begin{tabular}{|c|c|c|c|}
\hline $\begin{array}{c}\text { Role } \\
\text { (Loan offer flow) }\end{array}$ & $\begin{array}{c}\text { Financing } \\
\text { Mechanisms }\end{array}$ & Category & References \\
\hline Bank $\rightarrow$ Supplier & $\begin{array}{l}{ }^{*} \text { Receivables } \\
\text { Purchase (RP) }\end{array}$ & $\begin{array}{l}\text { Payables financing is provided through a buyer-led program } \\
\text { within which sellers in the buyer's supply chain are able to } \\
\text { access finance via RP. } \\
\text { Purchase order financing (or RP) allows banks to offer loans } \\
\text { to suppliers by considering the value of purchase orders } \\
\text { issued by reputable buyers and assessing the risk of the } \\
\text { supplier delivering the order successfully. } \\
\text { Factoring is a form of RP, in which firms sell their } \\
\text { creditworthy accounts receivable at a discount and receive } \\
\text { immediate cash. }\end{array}$ & $\begin{array}{c}\text { Babich and Kouvelis } \\
\qquad \text { (2018); } \\
\text { Reindorp et al. } \\
\text { (2018); Klapper } \\
\text { (2006) }\end{array}$ \\
\hline
\end{tabular}

Reverse factoring (RF), the most popular instrument among

the various supply chain financing schemes, initiated by

large firms with good credit ratings as a mechanism to

address their suppliers' financing problems.

Tanrisever et al. (2015) find that reverse factoring

Caniato (2016);

Factor $\rightarrow$ Supplier

Reverse

Factoring arrangements can create mutual value for both the buyer and supplier.

Devalkar and Krishnan (2018) find that reverse factoring arrangements along with delayed payment terms can restore supply chain efficiency by providing the supplier with access to inexpensive credit.
Tanrisever et al.

(2015); Devalkar and

Krishnan (2018)

\section{Supplier $\rightarrow$ Buyer $\quad$ Trade Credit highlighted:}

The advanced payment (AP) model: the downstream retailer makes an early payment to the supplier within a certain payment term.

The reverse factoring $(\mathrm{RF})$ model: the retailer cooperates with and encourages a bank to offer a loan to the supplier.

$\begin{array}{lr}\text { Buyer } \rightarrow \text { Supplier } & { }^{* *} \text { Working } \\ \text { Supplier } \rightarrow \text { Buyer } & \text { Capital }\end{array}$

Working capital aims to provide financial liquidity and viability for supply chain participants when trade credit is involved in their business transactions
Lee et al., 2018;

Tang et al., 2018;

Zhan et al., 2018;

Kouvelis and Zhao
HSBC UK

Luo and Shang

(2019); 


\begin{tabular}{ccc}
\hline Role & Financing & Category \\
(Loan offer flow) & Mechanisms & References \\
\hline
\end{tabular}

Marak and Pillai

Devalkar and

Krishnan (2018)

Source: Authors' Presentation

Note: *denotes The SCF mechanisms were developed from the Global SCF Forum classification, which includes receivables purchase, a range of loans,

and others defined by the author; ${ }^{* *}$ With trade credit, inventory decisions directly affect working capital levels as the deferred inventory payment and the delayed sales collection are recorded as accounts payable (A/P) and accounts receivable (A/R), respectively. Working capital supports the liquidity and financial viability of firms.

Table 1. SCF Practices 